\title{
AbsorÇão e Utilização do Nitrogênio pelas Culturas da SoJa e do FeiJão e por Plantas Daninhas ${ }^{1}$
}

\author{
Nitrogen Uptake and Use by Soybean and Bean Crops and by Weeds
}

PROCÓPIO, S.O. ${ }^{2}$, SANTOS, J.B. ${ }^{3}$, PIRES, F.R. ${ }^{2}$, SILVA, A.A. ${ }^{4}$ e MENDONÇA, E.S. ${ }^{5}$

\begin{abstract}
RESUMO - O objetivo deste trabalho foi avaliar a eficiência na absorção e utilização do nitrogênio (N) pelas culturas da soja e do feijão e por plantas daninhas freqüentemente encontradas nas áreas agrícolas do Brasil. O delineamento experimental utilizado foi o de blocos casualizados com três repetições, em esquema fatorial $6 \times 4$, sendo seis espécies vegetais: soja (Glycine max), feijão (Phaseolus vulgaris), dois biótipos de Euphorbia heterophylla (suscetivel e resistente aos herbicidas inibidores da ALS), Bidens pilosa e Desmodium tortuosum; e quatro doses de $\mathrm{N}\left(0,20,40\right.$ e $\left.80 \mathrm{mg} \mathrm{dm}^{-3}\right)$ avaliado em casa de vegetação. A aplicação do $\mathrm{N}$ foi realizada adicionando-se $60 \%$ do fertilizante sulfato de amônio ( $20 \%$ de N) na semeadura e o restante em cobertura, dividida em duas aplicações: 20 e 30 dias após plantio (DAP). A espécie vegetal que mais respondeu em aumento de área foliar, com a adição de doses crescentes de N, foi B. pilosa; todavia, nos tratamentos sem aplicação ou com a aplicação das menores doses desse nutriente, a soja apresentou a maior área foliar. Também a soja acumulou a maior biomassa em seu sistema radicular, tendendo, porém, a diminuir com a adição de N. B. pilosa e os biótipos de E. heterophylla aumentaram seu acúmulo de biomassa com o incremento do fornecimento de $\mathrm{N}$. Nenhuma espécie respondeu à adubação com $\mathrm{N}$ em relação ao aumento no teor desse nutriente em seus tecidos; entretanto, observou-se que as leguminosas apresentaram maior teor do que as espécies pertencentes às demais famílias. O conteúdo total de $\mathrm{N}$ nos tecidos da cultura da soja diminuiu com o aumento da dose aplicada; já para todas as espécies de plantas daninhas, o conteúdo acumulado de $\mathrm{N}$ aumentou com o incremento das doses. A maior eficiência das raízes na absorção de $\mathrm{N}$ foi constatada para as plantas de feijão. B. pilosa e os biótipos de E. heterophylla foram as espécies que demonstraram maior eficiência na utilização do $\mathrm{N}$ absorvido. O fornecimento de $\mathrm{N}$ favoreceu mais as espécies de plantas daninhas não pertencentes à família das leguminosas do que as culturas da soja e do feijão; por essa razão, um manejo inadequado desse nutriente nessas culturas pode agravar o problema da matocompetição.
\end{abstract}

Palavras-chave: Glycine max, Phaseolus vulgaris, Desmodium tortuosum, Bidens pilosa, Euphorbia heterophylla.

ABSTRACT - The objective of this work was to evaluate the efficiency in NITROGEN( N) uptake and use by soybean and bean crops and by weeds in agricultural areas in Brazil. A $6 \times 4$ factorial arrangement was employed on a randomized block design, with 6 plant species soybean (Glycine max), bean (Phaseolus vulgaris), two Euphorbia heterophylla (biotypes susceptible and resistant to $A L S$ - inhibiting herbicides), Bidens pilosa and Desmodium tortuosum; and 4 doses

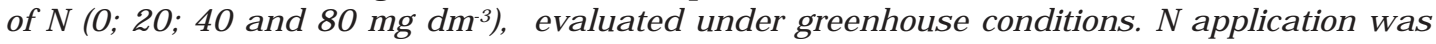
performed by adding 60\% of the fertilizer ammonium sulfate (20\% of $N$ ) in the seeding and the remainder in two applications, 20 and 30 days after planting (DAP). B. pilosa. showed the highest leaf area increase with the addition of increasing $N$ doses; however, soybean showed the highest leaf area in the treatments without $N$ application or with application of the smallest doses of this nutrient. Soybean also accumulated the highest biomass in its root system, decreasing with $N$ addition and B. pilosa and $\mathbf{E}$. heterophylla biotypes increased its biomass with increased $N$

Recebido para publicação em 26.3.2004 e na forma revisada em 10.9.2004.

2 Professor da Faculdade de Agronomia Eliseu Maciel, Departamento de Fitossanidade da Universidade Federal de Pelotas UFPEL, 96010-900 Pelotas-RS. ${ }^{3}$ Doutorando do Departamento de Fitotecnia da Universidade Federal de Viçosa - UFV, 36570-000 Viçosa-MG, <jbarbosasantos@yahoo.com.br>; ${ }^{4}$ Professor do Departamento de Fitotecnia - UFV; ${ }^{5}$ Professor do Departamento de Solos - UFV. 
supply. No species showed increased $N$ content in their tissues in response to $N$ fertilization; however, the leguminous plants showed a higher $N$ content than the species of the other families. Total $N$ content in the soybean tissues decreased with the increase of the dose applied while in the weed species, accumulated $N$ content increased with dose increase. The highest efficiency of $N$ uptake by the roots was verified in the bean plants. B. pilosa and E. heterophylla biotypes showed the highest efficiency in $N$ use. Weed species not belonging to the leguminous families took the most advantage from $N$ supplementation. Thus, inadequate $N$ management in these crops may worsen the problem of weed interference.

Key words: Glycine max, Phaseolus vulgaris, Desmodium tortuosum, Bidens pilosa, Euphorbia heterophylla.

\section{INTRODUÇÃO}

Dentre os fatores de competição entre as plantas cultivadas e as plantas daninhas, os nutrientes, principalmente nitrogênio $(\mathrm{N})$, fósforo $(\mathrm{P})$ e potássio (K), apresentam-se de grande importância no entendimento da perda de produção das culturas agrícolas. Embora se disponha atualmente de grande volume de conhecimento e avanços tecnológicos a respeito da nutrição mineral de espécies cultivadas, a falta de estudos sobre a nutrição mineral das plantas comumente infestantes das lavouras brasileiras prejudica o entendimento dos fatores que interferem na competição por nutrientes entre as plantas cultivadas e as plantas daninhas. Informações sobre as respostas de plantas daninhas a várias doses de fertilizante do solo são necessárias para o desenvolvimento de estratégias quanto à aplicação de fertilizantes, a qual constitui-se num componente fundamental de programas de manejo integrado de plantas daninhas (Blackshaw et al., 2003). De acordo com Anguinoni et al. (1989), a capacidade de absorção de nutrientes do solo pelas plantas depende da magnitude e da morfologia do seu sistema radicular e da eficiência na absorção desses elementos. Chapin (1980) afirma que algumas espécies de plantas daninhas absorvem mais nutrientes por unidade de biomassa radicular do que as culturas, atribuindo esse fato à seleção voltada à sobrevivência, sofrida pelas plantas daninhas.

A adubação nitrogenada em lavouras isentas de plantas daninhas apresenta benefícios evidentes, porém a sua eficiência em áreas infestadas ainda gera dúvidas (Eberhardt et al., 1999). Segundo Shafiq et al. (1994), entre os nutrientes, a maior competição entre plantas daninhas e espécies cultivadas se dá por $\mathrm{N}$.
Algumas espécies de plantas daninhas presentes em solos contendo elevados níveis de nutrientes tornam-se mais competitivas com as culturas, devido à sua maior eficiência na absorção e utilização desses nutrientes (Tomaso, 1995). Estudos realizados por Vengris et al. (1955) demonstraram que na competição entre o milho e plantas daninhas, o conteúdo de $\mathrm{N}$ era mais afetado negativamente para a cultura. Teyker et al. (1991) constataram que plantas de Amaranthus retroflexus que cresceram em associação com plantas de milho acumularam 2,5 veses mais $\mathrm{N}$, em relação a essa cultura, quando altos níveis desse elemento eram fornecidos. Ponce et al. (1996) constataram que plantas de tomate crescendo em associação com Solanum nigrum absorveram 2,73 g por planta de $\mathrm{N}$, enquanto aquelas que cresciam sem competição apresentaram absorção de $4,12 \mathrm{~g}$ por planta de N. Por outro lado, de acordo com Shafiq et al. (1994), aplicações de $\mathrm{N}$ podem reduzir a pressão de competição das plantas daninhas com determinadas culturas, por incrementar o crescimento e a habilidade competitiva das plantas cultivadas. Também, Shafiq et al. (1994) concluíram que a supressão provocada por plantas daninhas sobre a cultura do trigo foi maior em áreas que não receberam $\mathrm{N}$. Blackshaw et al. (2003) verificaram que todas as 23 espécies de plantas daninhas avaliadas em seu trabalho retiraram mais que $80 \%$ do $\mathrm{N}$ disponivel do solo, quando da aplicação de baixas doses desse nutriente.

Mesmo que diferentes espécies vegetais apresentem capacidade similar na absorção de um determinado nutriente, pode ocorrer grande diferença entre elas na produção de biomassa, resultante de diferenças na eficiência de utilização desses elementos (Furlani et al., 1986). Armstrong et al. (1993), avaliando 
a absorção e o uso de nutrientes por quatro gramíneas, verificaram que as espécies Cenchrus ciliaris e Digitaria ammophila apresentaram maior eficiência no uso do $\mathrm{N}$ em relação a plantas de Aristida armata e Thyridolepis mitchelliana.

O objetivo deste trabalho foi avaliar a eficiência na absorção e utilização do nitrogênio pelas culturas da soja e do feijão e por plantas daninhas de ocorrência freqüente nas áreas agrícolas do País, visando adquirir subsídios ao estabelecimento de estratégias para o fornecimento de nutrientes que favoreçam as culturas em detrimento das plantas daninhas.

\section{MATERIAL E MÉTODOS}

Foram utilizados vasos plásticos contendo $3 \mathrm{dm}^{3}$ de solo. As amostras de solo foram destorroadas, homogeneizadas, secadas ao ar e passadas em peneira de malha de $2 \mathrm{~mm}$. Em cada vaso foram semeadas cinco sementes, para as culturas, ou 20 sementes, para as plantas daninhas. Após o estabelecimento destas, foi realizado desbaste, deixando-se apenas uma planta por vaso. Os vasos receberam três irrigações diárias, para a manutenção da umidade do solo.

O delineamento experimental utilizado foi o de blocos casualizados com três repetições, sendo os tratamentos dispostos em esquema fatorial $6 \times 4$, com seis espécies vegetais [soja (cultivar Capinópolis), feijão (cultivar Pérola), Euphorbia heterophylla (suscetivel aos herbicidas inibidores de ALS), Euphorbia heterophylla (resistente aos herbicidas inibidores de ALS), Bidens pilosa e Desmodium tortuosum] e quatro doses de nitrogênio (N) [sem adição $\left(0 \mathrm{~kg} \mathrm{ha}^{-1}\right)$, metade da dose recomendada (50 kg ha-1), dose recomendada (100 kg ha-1) e duas vezes a dose recomendada $\left.\left(200 \mathrm{~kg} \mathrm{ha}^{-1}\right)\right]$, equivalentes a $0,20,40$ e $80 \mathrm{mg} \mathrm{dm}^{-3} \mathrm{de} \mathrm{N}$, respectivamente.

Os nutrientes fósforo (P) e potássio (K) foram fornecidos para todos os tratamentos em mesma quantidade, por ocasião da semeadura. A quantidade dos nutrientes fornecidos (NPK) foi determinada tomando-se como base a cultura do feijão e a análise do solo (Tabela 1). A aplicação do N foi realizada aplicando-se 60\% do fertilizante na semeadura e o restante em cobertura, dividida em duas aplicações: aos 20 e 30 dias após plantio (DAP), todos na forma de sulfato de amônio ( $20 \%$ de N).

$\mathrm{Na}$ época de avaliação (final da formação de propágulos), as plantas foram coletadas, sendo obtida a massa seca da parte aérea e das raízes. Foram realizadas medições da área foliar das plantas. Após essa etapa, a biomassa foi colocada em estufa com circulação forçada de ar a $75^{\circ} \mathrm{C}$, para secagem até peso constante. A quantificação da biomassa seca foi realizada em balança de precisão. Posteriormente, as amostras do tecido vegetal foram moídas em moinho tipo Wiley, de aço inoxidável, passadas em peneira de 20 mesh (malha por polegada 2 ) e acondicionadas em sacos de papel, para serem analisadas quimicamente.

Para determinação do teor de N-orgânico, as amostras foram mineralizadas por via úmida, em ácido sulfúrico concentrado, e o teor foi dosado usando-se o reagente de Nessler, com leitura em espectrofotômetro

Tabela 1 - Composição físico-química do solo Argissolo Vermelho-Amarelo utilizado no experimento

\begin{tabular}{|c|c|c|c|c|c|c|c|c|c|c|}
\hline \multicolumn{11}{|c|}{ Análise granulométrica $\left(\mathrm{dag} \mathrm{kg}^{-1}\right)$} \\
\hline \multicolumn{2}{|c|}{ Argila } & \multicolumn{2}{|l|}{ Silte } & Areia fina & \multicolumn{3}{|c|}{ Areia grossa } & \multicolumn{3}{|c|}{ Classificação textural } \\
\hline \multicolumn{2}{|c|}{39} & 11 & \multicolumn{2}{|r|}{17} & \multicolumn{3}{|c|}{33} & \multicolumn{3}{|c|}{ Argilo-arenosa } \\
\hline \multicolumn{11}{|c|}{ Análise Química } \\
\hline $\mathrm{pH}$ & $\mathrm{P}$ & $\mathrm{K}^{+}$ & $\mathrm{H}+\mathrm{Al}$ & $\mathrm{Al}^{3+}$ & $\mathrm{Ca}^{2+}$ & $\mathrm{Mg}^{2+}$ & $\mathrm{CTC}_{\text {total }}$ & $\mathrm{V}$ & $\mathrm{M}$ & $\mathrm{MO}$ \\
\hline$\left(\mathrm{H}_{2} \mathrm{O}\right)$ & \multicolumn{2}{|c|}{$\left(\mathrm{mg} \mathrm{dm}^{-3}\right)$} & \multicolumn{5}{|c|}{$\left(\mathrm{cmol}_{\mathrm{c}} \mathrm{dm}^{-3}\right)$} & \multicolumn{2}{|c|}{$(\%)$} & $\left(\right.$ dag kg $\left.^{-1}\right)$ \\
\hline 5,8 & 3,4 & 123 & 4,3 & 0,0 & 3,8 & 1,4 & 9,81 & 56 & 0 & 2,18 \\
\hline
\end{tabular}

Análises realizadas nos Laboratórios de Análises Físicas e Químicas de Solo do Departamento de Solos da UFV, segundo a metodologia descrita pela Empresa Brasileira de Pesquisa Agropecuária-EMBRAPA (1997). 
(Jackson, 1958). O N-inorgânico (nitrato) foi determinado usando-se tubos de ensaio em banho-maria, à temperatura de $45^{\circ} \mathrm{C}$, por uma hora. Após o resfriamento dos tubos, o extrato foi obtido pela adição de carvão ativado, seguido de agitação e filtração lenta. O teor de nitrato no extrato foi determinado, segundo a metodologia descrita por Cataldo et al. (1975), com leitura em espectrofotômetro.

Após coleta e tabulação dos dados, foram calculados os seguintes índices de eficiência de absorção e utilização do nitrogênio:

a) Eficiência na absorção de $\mathrm{N}$ (EAN): conteúdo de $\mathrm{N}$ na planta (mg)/biomassa seca de raízes (g).

b) Eficiência na utilização do $\mathrm{N}$ absorvido $\left(\mathrm{EUN}_{\mathrm{a}}\right)$ : biomassa seca total produzida (g)/ conteúdo de $\mathrm{N}$ na planta (mg).

Os dados foram submetidos à análise de variância. Os efeitos entre as espécies vegetais, dentro de cada dose do nutriente, foram avaliados pelo teste de Tukey a $5 \%$ de probabilidade. Os efeitos entre doses do nutriente, dentro de cada planta, foram analisados por meio de análise de regressão, sendo os modelos de regressão escolhidos com base na significância dos coeficientes da equação pelo teste $t$, no coeficiente de determinação $\left(R^{2}\right)$ e na adequação biológica.

\section{RESULTADOS E DISCUSSÃO}

Todas as espécies responderam com aumento na área foliar (AF) à adição de doses crescentes de N; contudo, a resposta verificada nas plantas de soja ocorreu até a dose de $40 \mathrm{mg} \mathrm{dm}^{-3}$ (Tabela 2). Tuor \& Froud-Williams (2002) não encontraram resposta da adubação de $\mathrm{N}$ sobre a altura, área foliar e biomassa em plantas de soja. O fornecimento de $\mathrm{N}$ acima desse nível causou prejuízo na formação de AF das plantas de soja (Tabela 3 e Figura 1). A cultura da soja apresentou maior AF em todas as doses de $\mathrm{N}$ avaliadas, quando comparada ao feijão, apresentando também maior AF em relação aos biótipos de E. heterophylla (Tabela 2). No entanto, as plantas de soja não diferiram de $D$. tortuosum e $B$. pilosa quando se aplicou a dose de $\mathrm{N}$ de $80 \mathrm{mg} \mathrm{dm}^{-3}$. D. tortuosum apresentou maior AF em relação ao feijão, em todas as doses de $\mathrm{N}$ avaliadas.

O feijão foi a única espécie que não apresentou variação na produção de biomassa seca de raízes (BSR) com a aplicação de doses crescentes de N (Tabela 4). B. pilosa e os biótipos de $E$. heterophylla mostraram resposta positiva e linear ao acréscimo de $\mathrm{N}$ (Tabela 3 e Figura 2). D. tortuosum apresentou resposta positiva ao aumento na BSR até, aproximadamente, $40 \mathrm{mg} \mathrm{dm}^{-3}$ de $\mathrm{N}$. A adição de $\mathrm{N}$ tendeu a causar diminuição da BSR de plantas de soja (Figura 2). Nos tratamentos contendo 0, 20 e $80 \mathrm{mg} \mathrm{dm}^{-3} \mathrm{de} \mathrm{N}$, a soja foi a espécie que apresentou a maior BSR entre todas as espécies avaliadas; todavia, quando da adição da dose recomendada de $\mathrm{N}$ com base na cultura do feijão $\left(40 \mathrm{mg} \mathrm{dm}^{-3}\right), D$. tortuosum teve a maior BSR (Tabela 4). A dimensão do sistema radicular é importante na absorção de íons,

Tabela 2 - Área foliar (AF) por planta na fase de formação de propágulos, das culturas do feijão e da soja e de espécies de plantas daninhas, submetidas a quatro doses de nitrogênio (N).Viçosa-MG, 2002

\begin{tabular}{|c|c|c|c|c|c|}
\hline \multirow{3}{*}{ Espécie } & \multicolumn{5}{|c|}{ Dose de $\mathrm{N}\left(\mathrm{mg} \mathrm{dm}^{-3}\right)$} \\
\hline & 0,0 & 20 & 40 & 80 & Média \\
\hline & \multicolumn{5}{|c|}{$\mathrm{AF}\left(\mathrm{cm}^{2}\right)$} \\
\hline P. vulgaris & $443,64 \mathrm{~b}$ & $545,58 \mathrm{~cd}$ & $690,67 \mathrm{c}$ & $773,82 \mathrm{c}$ & - \\
\hline G. Max & $928,35 \mathrm{a}$ & $1.733,82 \mathrm{a}$ & $1.854,24 \mathrm{a}$ & $1.607,78 \mathrm{a}$ & - \\
\hline E. heterophylla (resistente*) & $195,63 \mathrm{c}$ & $364,67 d$ & $637,25 \mathrm{c}$ & $1.027,53 \mathrm{~b}$ & - \\
\hline E. heterophylla (sensível*) & $260,83 \mathrm{bc}$ & $360,90 \mathrm{~d}$ & $658,46 \mathrm{c}$ & $996,33 \mathrm{~b}$ & - \\
\hline B. pilosa & $316,79 \mathrm{bc}$ & $627,77 \mathrm{c}$ & $969,76 \mathrm{~b}$ & $1.701,89 \mathrm{a}$ & - \\
\hline D. tortuosum & $1.116,14 \mathrm{a}$ & $1.100,26 \mathrm{~b}$ & $1.136,03 \mathrm{~b}$ & $1.658,85 \mathrm{a}$ & - \\
\hline
\end{tabular}

* Biótipo resistente e sensível aos herbicidas inibidores da ALS.

Médias seguidas de letras iguais, na coluna, não diferem entre si pelo teste de Tukey a 5\% de probabilidade. 
Tabela 3 - Equações de regressão dos diferentes parâmetros avaliados para as culturas do feijão e da soja e para plantas daninhas, em resposta a doses (D) de nitrogênio (N)

\begin{tabular}{|c|c|c|c|c|}
\hline Espécie & Área foliar por planta & $\mathrm{R}^{2}$ & Biomassa seca de raízes & $\mathrm{R}^{2}$ \\
\hline P. vulgaris & $\hat{\mathrm{Y}}=434,4593+7,6128 \mathrm{D}-0,0414 \mathrm{D}^{2}$ & 0,98 & - & - \\
\hline G. $\max$ & $\hat{\mathrm{Y}}=971,11+40,6512 \mathrm{D}-0,4113 \mathrm{D}^{2}$ & 0,96 & $\hat{\mathrm{Y}}=11,6613-0,1521 \mathrm{D}+0,0018 \mathrm{D}^{2}$ & 0,79 \\
\hline E. heterophylla (resistente*) & $\hat{\mathrm{Y}}=185,1894+10,6023 \mathrm{D}$ & 0,99 & $\hat{\mathrm{Y}}=0,7750+0,0300 \mathrm{D}$ & 0,99 \\
\hline E. heterophylla $($ sensível*) & $\hat{\mathrm{Y}}=233,28+9,5955 \mathrm{D}$ & 0,98 & $\begin{array}{l}\hat{\mathrm{Y}}=1,0806+0,0090 \mathrm{D} \\
\end{array}$ & 0,97 \\
\hline B. pilosa & $\hat{\mathrm{Y}}=294,7584+17,4084 \mathrm{D}$ & 0,99 & $\hat{\mathrm{Y}}=2,6176+0,0300 \mathrm{D}$ & 0,86 \\
\hline D. tortuosum & $\hat{\mathrm{Y}}=1124,2182-5,2506 \mathrm{D}+0,1487 \mathrm{D}^{2}$ & 0,99 & $\hat{\mathrm{Y}}=4,5503+0,2268 \mathrm{D}-0,0027 \mathrm{D}^{2}$ & 0,79 \\
\hline Espécie & Conteúdo total de $\mathrm{N}$ na planta & $\mathrm{R}^{2}$ & Eficiência na absorção de $\mathrm{N}$ (EAN) & $\mathrm{R}^{2}$ \\
\hline P. vulgaris & - & - & $\hat{\mathrm{Y}}=101,8837+1,6188 \mathrm{D}-0,0171 \mathrm{D}^{2}$ & 0,92 \\
\hline G. $\max$ & $\hat{\mathrm{Y}}=715,9722-4,3305 \mathrm{D}+0,0324 \mathrm{D}^{2}$ & 0,78 & - & - \\
\hline $\begin{array}{l}\text { E. heterophylla (resistente*) } \\
\text { (2) }\end{array}$ & $\hat{\mathrm{Y}}=483,4785-6,9564 \mathrm{D}+0,1161 \mathrm{D}^{2}$ & 0,99 & $\begin{array}{l}\hat{\mathrm{Y}}=50,4038+1,4442 \mathrm{D}-0,0117 \mathrm{D}^{2} \\
=\end{array}$ & 0,99 \\
\hline E. heterophylla (sensível*) & $\hat{\mathrm{Y}}=53,2048+2,4135 \mathrm{D}-0,0135 \mathrm{D}^{2}$ & 0,99 & - & - \\
\hline B. pilosa & $\hat{\mathrm{Y}}=74,9738-0,0573 \mathrm{D}+0,0441 \mathrm{D}^{2}$ & 0,99 & $\hat{\mathrm{Y}}=31,3411-0,3921 \mathrm{D}+0,0117 \mathrm{D}^{2}$ & 0,99 \\
\hline D. tortuosum & $\hat{\mathrm{Y}}=37,6081+2,1765 \mathrm{D}+0,0027 \mathrm{D}^{2}$ & 0,99 & $\hat{\mathrm{Y}}=96,187-2,7324 \mathrm{D}+0,0324 \mathrm{D}^{2}$ & 0,98 \\
\hline
\end{tabular}

* Biótipo resistente e sensível aos herbicidas inibidores da ALS.

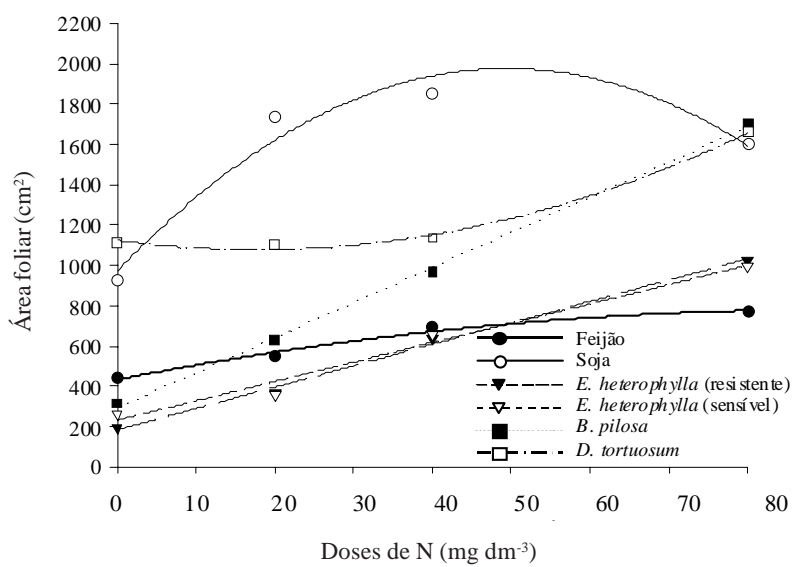

Figura 1 - Área foliar por planta, determinada na fase final de formação de propágulos, das culturas do feijão e da soja e de plantas daninhas, em resposta a doses de nitrogênio (N).

cujo fornecimento para a raiz ocorre, principalmente, pelo processo de difusão (Canal \& Mielniczuk, 1983). Maior investimento na produção de raízes, principalmente nos estádios iniciais de desenvolvimento, pode representar uma estratégia de competição por nutrientes.

B. pilosa e os biótipos de E. heterophylla apresentaram aumento de biomassa seca

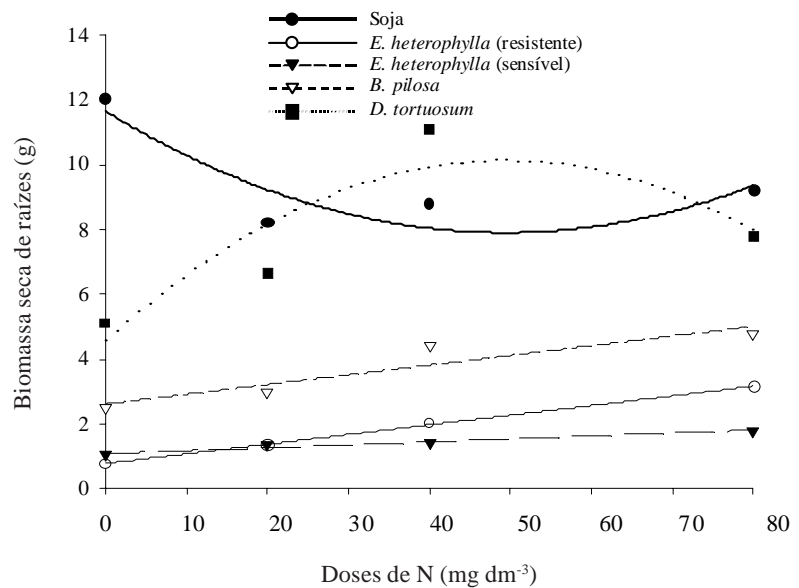

Figura 2 - Biomassa seca de raízes por planta, determinada na fase final de formação de propágulos, para a cultura da soja e para espécies de plantas daninhas, em resposta a doses de nitrogênio $(\mathrm{N})$.

total (BST) com o incremento nas doses de $\mathrm{N}$ (Figura 3). Blackshaw et al. (2003) observaram que as biomassas da parte aérea e das raízes de 23 espécies de plantas daninhas apresentaram aumento com a adição de $\mathrm{N}$ ao solo, porém a magnitude das respostas variou entre as espécies. Nos tratamentos em que foram aplicados 20 ou $40 \mathrm{mg} \mathrm{dm}^{-3} \mathrm{de} \mathrm{N}$, soja e 
D. tortuosum foram as espécies que produziram a maior BST; entretanto, com a adição do maior nível de $\mathrm{N}\left(80 \mathrm{mg} \mathrm{dm}^{-3}\right), D$. tortuosum produziu a maior BST (Tabela 5). A rápida acumulação de biomassa na parte aérea de uma planta resulta em aumento na demanda e, conseqüentemente, na absorção de nutrientes pelas raízes (Chapin, 1980). As plantas de feijão sempre acumularam menor BST em relação à soja, independentemente do nível de $\mathrm{N}$ fornecido. O biótipo de $E$. heterophylla resistente aos herbicidas inibidores da ALS apresentou maior BST em comparação com o biótipo sensível nos tratamentos em que se aplicaram as duas maiores doses de N (40 e $80 \mathrm{mg} \mathrm{dm}^{-3}$ ). De acordo com Wahle \& Masiunas (2003), a planta daninha Solanum ptycanthum é favorecida em ambiente contendo altas doses de $\mathrm{N}$.

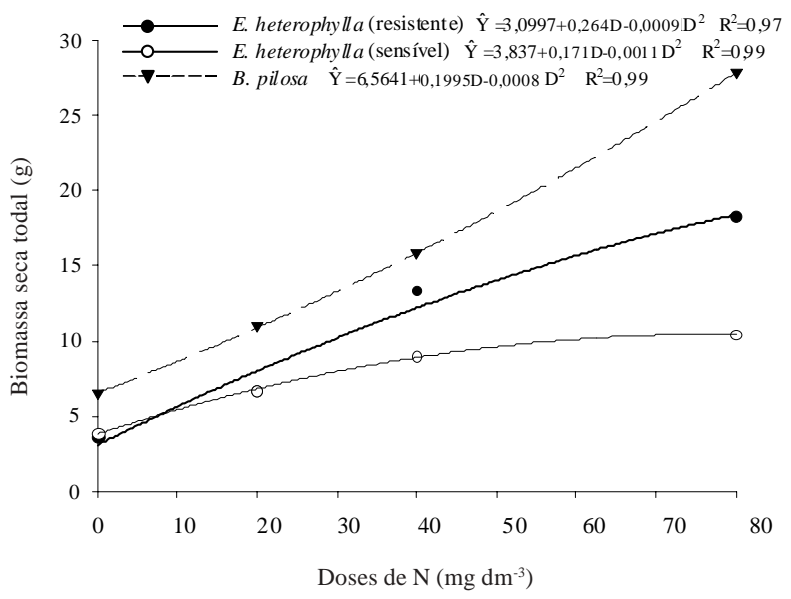

Figura 3 - Biomassa seca total por planta, determinada na fase final de formação de propágulos, das espécies Euphorbia heterophylla (resistente e suscetível) e Bidens pilosa, em resposta a doses de nitrogênio $(\mathrm{N})$.

Tabela 4 - Biomassa seca de raízes (BSR) por planta na fase de formação de propágulos, das culturas do feijão e da soja e de espécies de plantas daninhas, submetidas a quatro doses de nitrogênio (N). Viçosa-MG, 2002

\begin{tabular}{|c|c|c|c|c|c|}
\hline \multirow{3}{*}{ Espécie } & \multicolumn{5}{|c|}{ Dose de $\mathrm{N}\left(\mathrm{mg} \mathrm{dm}^{-3}\right)$} \\
\hline & 0,0 & 20 & 40 & 80 & Média \\
\hline & \multicolumn{5}{|c|}{ BSR $(g)$} \\
\hline P. vulgaris & $1,67 \mathrm{~d}$ & $1,42 \mathrm{~d}$ & $1,33 \mathrm{e}$ & $1,78 \mathrm{e}$ & $\bar{Y}=1,55$ \\
\hline G. Max & $12,04 \mathrm{a}$ & $8,21 \mathrm{a}$ & $8,81 \mathrm{~b}$ & $9,23 \mathrm{a}$ & - \\
\hline E. heterophylla (resistente*) & $0,76 \mathrm{e}$ & $1,35 \mathrm{~d}$ & $2,04 \mathrm{~d}$ & $3,13 \mathrm{~d}$ & - \\
\hline E. heterophylla (sensível*) & $1,03 \mathrm{de}$ & $1,34 \mathrm{~d}$ & $1,42 \mathrm{de}$ & $1,80 \mathrm{e}$ & - \\
\hline B. pilosa & $2,48 \mathrm{c}$ & $2,99 \mathrm{c}$ & $4,44 \mathrm{c}$ & $4,76 \mathrm{c}$ & - \\
\hline D. tortuosum & $5,12 \mathrm{~b}$ & $6,65 \mathrm{~b}$ & $11,08 \mathrm{a}$ & $7,77 \mathrm{~b}$ & - \\
\hline
\end{tabular}

* Biótipo resistente e sensível aos herbicidas inibidores da ALS.

Médias seguidas de letras iguais, na coluna, não diferem entre si pelo teste de Tukey a 5\% de probabilidade.

Tabela 5 - Biomassa seca total (BST) por planta das culturas do feijão e da soja e de espécies de plantas daninhas, submetidas a quatro doses de nitrogênio (N). Viçosa-MG, 2002

\begin{tabular}{|c|c|c|c|c|c|}
\hline \multirow{3}{*}{ Espécie } & \multicolumn{5}{|c|}{ Dose de $\mathrm{N}\left(\mathrm{mg} \mathrm{dm}^{-3}\right)$} \\
\hline & 0,0 & 20 & 40 & 80 & Média \\
\hline & \multicolumn{5}{|c|}{$\mathrm{BST}(\mathrm{g})$} \\
\hline P. vulgaris & $5,85 \mathrm{~b}$ & $5,95 \mathrm{c}$ & $6,60 \mathrm{c}$ & $6,79 \mathrm{e}$ & $\overline{\mathrm{Y}}=6,30$ \\
\hline G. Max & $25,39 \mathrm{a}$ & $23,46 \mathrm{a}$ & $22,70 \mathrm{a}$ & $23,02 \mathrm{c}$ & $\bar{Y}=23,64$ \\
\hline E. heterophylla (resistente*) & $3,63 \mathrm{~b}$ & $6,61 \mathrm{c}$ & $13,26 \mathrm{~b}$ & $18,24 \mathrm{~d}$ & - \\
\hline E. heterophylla (sensível*) & $3,87 \mathrm{~b}$ & $6,71 \mathrm{c}$ & $8,99 \mathrm{c}$ & $10,43 \mathrm{e}$ & - \\
\hline B. pilosa & $6,54 \mathrm{~b}$ & $10,95 \mathrm{~b}$ & $15,83 \mathrm{~b}$ & $27,84 \mathrm{~b}$ & - \\
\hline D. tortuosum & $23,60 \mathrm{a}$ & $27,40 \mathrm{a}$ & $26,40 \mathrm{a}$ & $33,94 \mathrm{a}$ & $\overline{\mathrm{Y}}=27,83$ \\
\hline
\end{tabular}

* Biótipo resistente e sensível aos herbicidas inibidores da ALS.

Médias seguidas de letras iguais, na coluna, não diferementre si pelo teste de Tukey a 5\% de probabilidade. 
Não foi constatado aumento no teor de N das espécies avaliadas com a adição crescente desse nutriente (Tabela 6). No entanto, Rodrigues (2001) relata que o incremento de $\mathrm{N}$ na adubação elevou os teores foliares desse nutriente em plantas de feijoeiro.

A soja e o feijão apresentaram teores de $\mathrm{N}$ em seus tecidos muito próximos, apenas sendo maior no feijão quando se aplicaram $80 \mathrm{mg} \mathrm{dm}^{-3}$ desse elemento. Entre as plantas daninhas, D. tortuosum apresentou maior teor de $\mathrm{N}$ em seus tecidos, em todas as doses de $\mathrm{N}$, apenas não diferindo do biótipo de E. heterophylla suscetivel aos herbicidas inibidores da ALS na maior concentração de $\mathrm{N}$ (80 $\mathrm{mg} \mathrm{dm}^{-3}$ ) (Tabela 6). Vengris et al. (1955) encontraram os teores de $\mathrm{N}$ na biomassa seca das plantas daninhas Amaranthus retroflexus, Chenopodium album, Digitaria sanguinalis e Echinochloa cruss-galli de 4,36; 5,30; 4,26; e $3,82 \%$, respectivamente. Não se detectaram diferenças quanto ao teor de $\mathrm{N}$ entre os biótipos de E. heterophylla. Souza et al. (1999), analisando o teor de $\mathrm{N}$ na biomassa seca da parte aérea de 17 espécies de plantas daninhas, encontraram os teores de 2,52 e 2,38\% para B. pilosa e E. heterophylla, respectivamente. Em decorrência dos resultados apresentados na Tabela 6, percebe-se maior teor de $\mathrm{N}$ nos tecidos das espécies pertencentes à família das leguminosas. Ugen et al. (2002), trabalhando em campo, constataram maior concentração de $\mathrm{N}$ na biomassa seca de plantas de feijão (33,5 a 35,4 $\mathrm{mg} \mathrm{g}^{-1}$ ), quando comparada às plantas daninhas Solanum nigrum $(23,7$ a
25,6 $\mathrm{mg} \mathrm{g}^{-1}$ ), Bidens pilosa (30,9 a 31,4 $\mathrm{mg} \mathrm{g}^{-1}$ ) e Galinsoga parviflora (19,4 a 29,6 $\mathrm{mg} \mathrm{g}^{-1}$ ), concordando com os resultados encontrados neste trabalho. No entanto, Gasem (1992), comparando a composição mineral da parte aérea de plantas de feijão e das plantas daninhas Chenopodium murale, Cichorium pumilum, Malva sylvestris, Sonchus oleraceus, Portulaca oleracea, Sisymbrium irio e Rumex obtusifolius, observou maior teor de N na biomassa das plantas daninhas em relação à determinada no feijoeiro.

A espécie em que se encontrou maior conteúdo de $\mathrm{N}$ em seus tecidos, independente do fornecimento de $\mathrm{N}$ ao solo, foi a soja, sendo equiparada apenas a $D$. tortuosum na dose de $80 \mathrm{mg} \mathrm{dm}^{-3}$ de N (Tabela 7). Esta, por sua vez, foi a espécie de planta daninha que apresentou maior quantidade de $\mathrm{N}$ em seus tecidos, em todas as doses de $\mathrm{N}$ fornecidas. O feijão acumulou menos $\mathrm{N}$ do que a soja e o $D$. tortuosum e foi a única espécie que não apresentou variação significativa no conteúdo desse nutriente com as doses fornecidas (Tabela 7). B. pilosa e os biótipos de E. heterophylla apresentaram resposta positiva em relação ao conteúdo de $\mathrm{N}$ com a adição desse nutriente ao solo. $\mathrm{O}$ conteúdo de $\mathrm{N}$ em plantas de $D$. tortuosum apenas aumentou no tratamento que recebeu a dose mais alta de N (Tabela 3 e Figura 4). Doses mais altas deste nutriente $(40$ e $80 \mathrm{mg} \mathrm{dm}^{-3}$ ) provocaram diminuição do conteúdo de $\mathrm{N}$ das plantas de soja. Analisando os dados, nota-se que as espécies não pertencentes à família das leguminosas, por não

Tabela 6 - Teor de nitrogênio $(\mathrm{N})$ encontrado nas culturas do feijão e da soja e em espécies de plantas daninhas, na fase final de formação de propágulos, submetidas a quatro doses de N. Viçosa-MG, 2002

\begin{tabular}{|c|c|c|c|c|c|}
\hline \multirow{3}{*}{ Espécie } & \multicolumn{5}{|c|}{ Dose de $\mathrm{N}\left(\mathrm{mg} \mathrm{dm}^{-3}\right)$} \\
\hline & 0,0 & 20 & 40 & 80 & Média \\
\hline & \multicolumn{5}{|c|}{ Teor de $\mathrm{N}\left(\mathrm{mg} \mathrm{g}^{-1}\right)$} \\
\hline P. vulgaris & $29,8 \mathrm{a}$ & $29,0 \mathrm{a}$ & $28,6 \mathrm{a}$ & $32,1 \mathrm{a}$ & $\overline{\mathrm{Y}}=29,9$ \\
\hline G. Max & $27,6 \mathrm{a}$ & $29,5 \mathrm{a}$ & $24,7 \mathrm{a}$ & $25,2 \mathrm{~b}$ & $\overline{\mathrm{Y}}=26,7$ \\
\hline E. heterophylla (resistente*) & $11,1 \mathrm{c}$ & $11,2 \mathrm{~cd}$ & $10,3 \mathrm{~b}$ & $12,5 \mathrm{~d}$ & $\overline{\mathrm{Y}}=11,3$ \\
\hline E. heterophylla (sensível*) & $13,3 \mathrm{c}$ & $15,2 \mathrm{c}$ & $13,9 \mathrm{~b}$ & $15,5 \mathrm{~cd}$ & $\overline{\mathrm{Y}}=14,5$ \\
\hline B. pilosa & $11,6 \mathrm{c}$ & $8,3 \mathrm{~d}$ & $9,2 \mathrm{~b}$ & $12,6 \mathrm{~d}$ & $\overline{\mathrm{Y}}=10,4$ \\
\hline D. tortuosum & $20,5 \mathrm{~b}$ & $22,4 \mathrm{~b}$ & $23,9 \mathrm{a}$ & $19,8 \mathrm{bc}$ & $\bar{Y}=21,6$ \\
\hline
\end{tabular}

* Biótipo resistente e sensível aos herbicidas inibidores da ALS.

Médias seguidas de letras iguais, na coluna, não diferem entre si pelo teste de Tukey a 5\% de probabilidade. 
fixarem $\mathrm{N}_{2}$ atmosférico, foram as que apresentaram as melhores respostas à adição de doses crescentes de N.

O feijão apresentou maior eficiência na absorção de N (EAN) do que as plantas de soja, quando submetido a todas as doses desse nutriente (Tabela 8). Soja e o biótipo resistente de E. heterophylla não apresentaram diferenças significativas na EAN em função de doses crescentes de N. O biótipo suscetivel de $E$. heterophylla apresentou incremento na EAN com o aumento nas doses desse nutriente. Para B. pilosa, isso só ocorreu com o fornecimento de altas doses (Tabela 3 e Figura 5). Feijão e D. tortuosum mostraram comportamentos contrários: enquanto a EAN do feijão foi maior no tratamento que recebeu a adição de $40 \mathrm{mg} \mathrm{dm}^{-3}$ de $\mathrm{N}$, para $D$. tortuosum esse nível de $\mathrm{N}$ ocasionou a EAN mais baixa entre as doses avaliadas.
A única espécie que apresentou variação na eficiência de utilização de N (EUN) com o

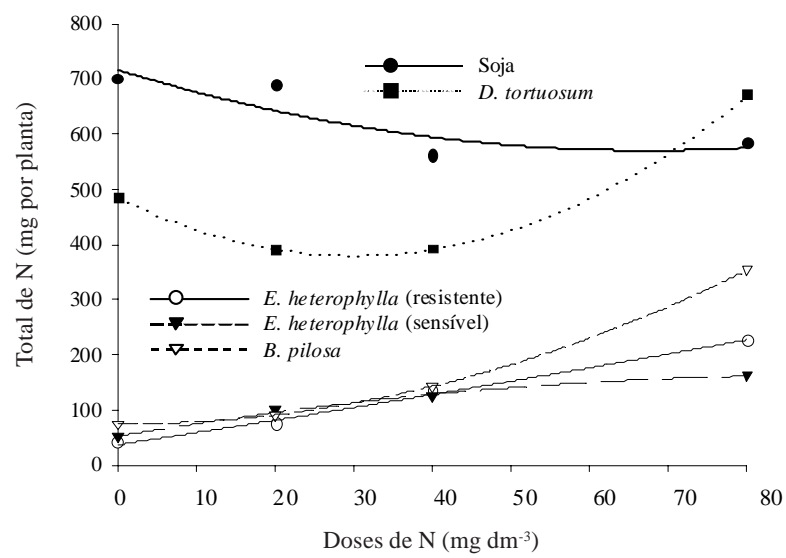

Figura 4 - Conteúdo total de nitrogênio $(\mathrm{N})$ nas plantas de soja e em espécies de plantas daninhas, na fase final de formação de propágulos, em resposta a doses desse nutriente.

Tabela 7 - Conteúdo total de nitrogênio $(\mathrm{N})$ por planta (NPLANTA) nas culturas do feijão e da soja e em espécies de plantas daninhas, na fase final de formação de propágulos, submetidas a quatro doses de N. Viçosa-MG, 2002

\begin{tabular}{|c|c|c|c|c|c|}
\hline \multirow{3}{*}{ Espécie } & \multicolumn{5}{|c|}{ Dose de $\mathrm{N}\left(\mathrm{mg} \mathrm{dm}^{-3}\right)$} \\
\hline & 0,0 & 20 & 40 & 80 & Média \\
\hline & \multicolumn{5}{|c|}{ NPLANTA (mg) } \\
\hline P. vulgaris & $174,58 \mathrm{c}$ & $171,12 \mathrm{c}$ & $190,05 \mathrm{c}$ & $213,05 \mathrm{c}$ & $\overline{\mathrm{Y}}=187,20$ \\
\hline G. Max & $699,21 \mathrm{a}$ & $686,92 \mathrm{a}$ & $560,64 \mathrm{a}$ & $580,79 \mathrm{a}$ & - \\
\hline E. heterophylla (resistente*) & $40,63 \mathrm{~d}$ & $74,07 \mathrm{c}$ & $134,70 \mathrm{c}$ & $226,64 \mathrm{c}$ & - \\
\hline E. heterophylla (sensível*) & $51,38 \mathrm{~d}$ & $101,03 \mathrm{c}$ & $124,92 \mathrm{c}$ & $162,15 \mathrm{c}$ & - \\
\hline B. pilosa & $75,18 \mathrm{~cd}$ & $91,12 \mathrm{c}$ & $144,08 \mathrm{c}$ & $353,55 \mathrm{~b}$ & - \\
\hline D. tortuosum & $483,90 \mathrm{~b}$ & $389,70 \mathrm{~b}$ & $391,98 \mathrm{~b}$ & $670,47 \mathrm{a}$ & - \\
\hline
\end{tabular}

* Biótipo resistente e sensível aos herbicidas inibidores da ALS.

Médias seguidas de letras iguais, na coluna, não diferem entre si pelo teste de Tukey a 5\% de probabilidade.

Tabela 8 - Eficiência na absorção de nitrogênio (N) (EAN) na fase final de formação de propágulos, das culturas do feijão e da soja e de espécies de plantas daninhas, submetidas a quatro doses de N. Viçosa-MG, 2002

\begin{tabular}{|l|c|c|c|c|c|}
\hline \multirow{2}{*}{ Espécie } & \multicolumn{5}{|c|}{ Dose de $\mathrm{N}\left(\mathrm{mg} \mathrm{dm}^{-3}\right)$} \\
\cline { 2 - 6 } & 0,0 & 20 & 40 & \multicolumn{3}{c|}{80} & Média \\
\cline { 2 - 6 } & \multicolumn{5}{|c|}{ EAN $\left(\mathrm{mg} \mathrm{g}^{-1}\right)$} \\
\hline P. vulgaris & $104,07 \mathrm{a}$ & $121,48 \mathrm{a}$ & $143,25 \mathrm{a}$ & $119,63 \mathrm{a}$ & - \\
\hline G. Max & $58,04 \mathrm{~b}$ & $83,62 \mathrm{~b}$ & $63,79 \mathrm{bcd}$ & $63,02 \mathrm{~b}$ & $\overline{\mathrm{Y}}=67,11$ \\
\hline E. heterophylla (resistente*) & $53,32 \mathrm{~b}$ & $55,23 \mathrm{bc}$ & $65,89 \mathrm{bc}$ & $72,19 \mathrm{~b}$ & $\overline{\mathrm{Y}}=61,66$ \\
\hline E. heterophylla (sensível*) & $50,14 \mathrm{~b}$ & $75,37 \mathrm{~b}$ & $89,09 \mathrm{~b}$ & $91,85 \mathrm{ab}$ & - \\
\hline B. pilosa & $30,47 \mathrm{~b}$ & $30,45 \mathrm{c}$ & $32,43 \mathrm{~d}$ & $74,33 \mathrm{~b}$ & - \\
\hline D. tortuosum & $94,47 \mathrm{a}$ & $59,13 \mathrm{bc}$ & $35,48 \mathrm{~cd}$ & $86,28 \mathrm{ab}$ & - \\
\hline
\end{tabular}

* Biótipo resistente e sensível aos herbicidas inibidores da ALS.

Médias seguidas de letras iguais, na coluna, não diferem entre si pelo teste de Tukey a 5\% de probabilidade. 
aumento da dose foi B. pilosa (Figura 6). Para essa espécie, constatou-se que o cultivo em solo que recebeu doses intermediárias de $\mathrm{N}$ (20 ou $40 \mathrm{mg} \mathrm{dm}^{-3}$ ) resultou em EUN maior. Também B. pilosa e os biótipos de E. heterophylla apresentaram a melhor EUN em relação às demais espécies avaliadas, incluindo a soja e o feijão, que não diferiram entre si em relação a esse índice (Tabela 9). Os resultados corroboram os encontrados por Eberhardt et al. (1999), os quais verificaram que dois ecótipos de arroz-vermelho foram mais eficientes que o arroz no uso do N, apresentando EUN entre 44,8 e 47,5 ( $\mathrm{g} \mathrm{BS} \mathrm{g}^{-1} \mathrm{~N}$ ), contra EUN de 36,7 (g BS g ${ }^{-1} \mathrm{~N}$ ) para o arroz,

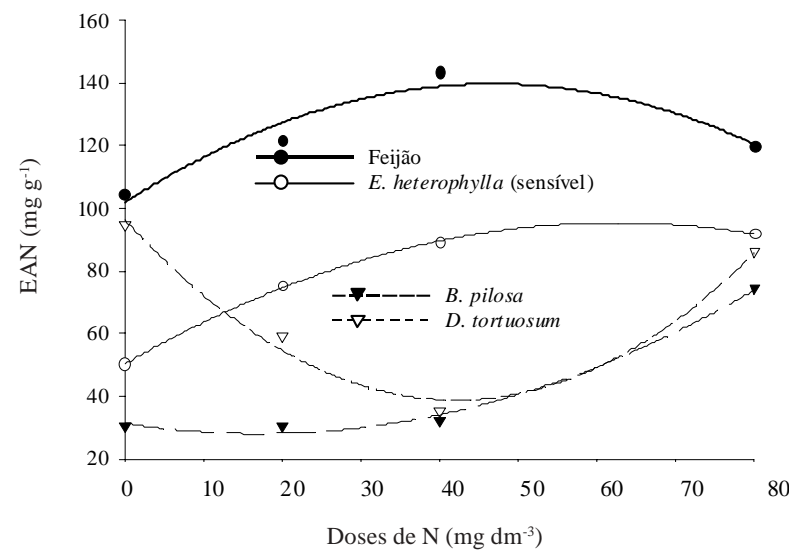

Figura 5 - Eficiência na absorção de nitrogênio (N) (EAN) pela cultura do feijão e por espécies de plantas daninhas, na fase final de formação de propágulos, em resposta a doses desse nutriente. avaliado no início do desenvolvimento da panícula. Carlson \& Hill (1985) verificaram que a planta daninha Avena fatua mostrou maior eficiência no uso do $\mathrm{N}$ do que plantas de trigo.

De maneira geral, o fornecimento de $\mathrm{N}$ favoreceu mais as espécies de plantas daninhas não pertencentes à família das leguminosas do que as culturas da soja e do feijão. Em decorrência disso, o manejo inadequado desse nutriente - como o uso de dose excessiva, época das aplicações inadequadas e a localização do fertilizante - pode agravar o problema da matocompetição nessas culturas.

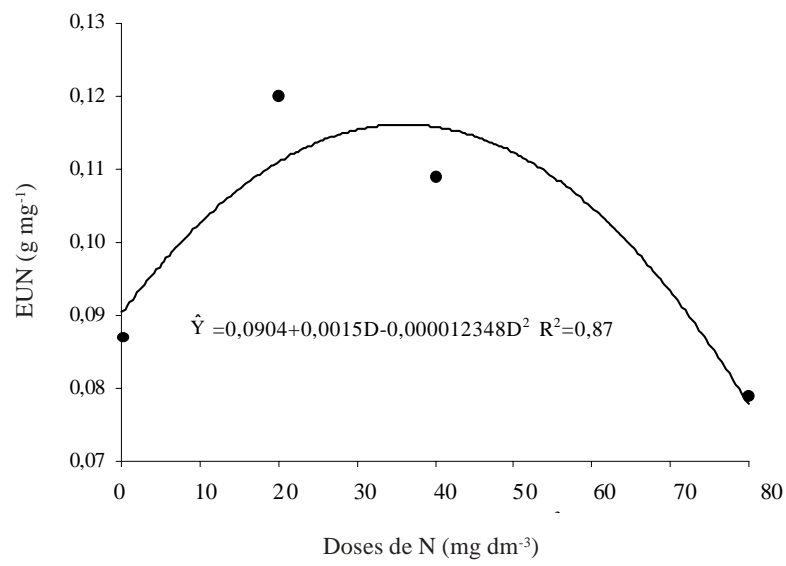

Figura 6 - Eficiência na utilização de nitrogênio (N) (EUN), por Bidens pilosa, na fase final de formação de propágulos, em resposta a doses desse nutriente.

Tabela 9 - Eficiência na utilização de nitrogênio (N) (EUN), pelas culturas do feijão e da soja e por espécies de plantas daninhas, na fase final formação de propágulos, submetidas a quatro doses de N. Viçosa-MG, 2002

\begin{tabular}{|c|c|c|c|c|c|}
\hline \multirow{3}{*}{ Espécie } & \multicolumn{5}{|c|}{ Dose de $\mathrm{N}\left(\mathrm{mg} \mathrm{dm}^{-3}\right)$} \\
\hline & 0,0 & 20 & 40 & 80 & Média \\
\hline & \multicolumn{5}{|c|}{ EUN $\left(\mathrm{g} \mathrm{mg}^{-1}\right)$} \\
\hline P. vulgaris & $0,033 \mathrm{~b}$ & $0,035 \mathrm{c}$ & $0,035 \mathrm{c}$ & $0,031 \mathrm{c}$ & $\overline{\mathrm{Y}}=0,033$ \\
\hline G. Max & $0,036 \mathrm{~b}$ & $0,034 \mathrm{c}$ & $0,040 \mathrm{c}$ & $0,040 \mathrm{c}$ & $\overline{\mathrm{Y}}=0,037$ \\
\hline E. heterophylla (resistente*) & $0,091 \mathrm{a}$ & $0,089 \mathrm{~b}$ & $0,098 \mathrm{a}$ & $0,086 \mathrm{a}$ & $\overline{\mathrm{Y}}=0,091$ \\
\hline E. heterophylla (sensível*) & $0,076 \mathrm{a}$ & $0,068 \mathrm{~b}$ & $0,074 \mathrm{~b}$ & $0,066 \mathrm{ab}$ & $\overline{\mathrm{Y}}=0,071$ \\
\hline B. pilosa & $0,087 \mathrm{a}$ & $0,120 \mathrm{a}$ & $0,109 \mathrm{a}$ & $0,079 \mathrm{a}$ & - \\
\hline D. tortuosum & $0,049 \mathrm{~b}$ & $0,045 \mathrm{c}$ & $0,042 \mathrm{c}$ & $0,051 \mathrm{bc}$ & $\bar{Y}=0,047$ \\
\hline
\end{tabular}

* Biótipo resistente e sensível aos herbicidas inibidores da ALS.

Médias seguidas de letras iguais, na coluna, não diferem entre si pelo teste de Tukey a 5\% de probabilidade. 


\section{AGRADECIMENTOS}

Ao $\mathrm{CNPq}$, pelo apoio financeiro a este projeto.

\section{LITERATURA CITADA}

ANGUINONI, I. et al. Morfologia de raízes e cinética da absorção de nutrientes em diversas espécies e genótipos de plantas. R. Bras. Ci. Solo, v. 13, p. 355-361, 1989.

ARMSTRONG, R. D.; BROWN, R. F.; HELYAR, K. R. The use of nitrogen, phosphorus and lime to limit the competitive ability of Aristida armata in the establishment phase. Aust. J. Agric. Res. , v. 44, p. 167-178, 1993.

BLACKSHAW, R. E. et al. Differential response of weed species to added nitrogen. Weed Sci., v. 51, p. 532-539, 2003.

CANAL, I. N.; MIELNICZUK, J. Parâmetros de absorção de potássio em milho (Zea mays L.), afetadas pela interação alumínio-cálcio. Ci. Cultura, v. 35, p. 336-340, 1983.

CARLSON, H. L.; HILL, J. E. Wild oat (Avena fatua) competition with spring wheat: Effects of nitrogen fertilization. Weed Sci., v. 34, p. 29-33, 1985.

CATALDO, D. A. et al. Rapid colorimetric determination of nitrate in plant tissues by nitratation of salicylic acid. Comm Soil Plant Anal., v. 6, p. 71-80, 1975.

CHAPIN, F. S. The mineral nutrition of wild plants. Ann. Rev. Ecol. Syst., v. 11, p. 235-260, 1980.

EBERHARDT, D. S.; SILVA, P. R. F.; RIEFFEL NETO, S. R. Eficiência de absorção e utilização de nitrogênio por plantas de arroz e de dois ecótipos de arroz vermelho. Planta Daninha, v. 17, p. 309-323, 1999.

EMPRESA BRASILEIRA DE PESQUISA AGROPECUÁRIA - EMBRAPA. Centro Nacional de Pesquisa de Solos. Manual de métodos de análise de solo. 2.ed. Rio de Janeiro, 1997. 212 p.

FURLANI, A. M. C.; BATAGLIA, O. C.; AZZINI, L. E. Variabilidade entre linhagens de arroz na absorção e utilização de potássio em solução nutritiva. R. Bras. Ci. Solo, v. 10, p. 135-141, 1986.
JACKSON, M. L. Nitrogen determinations for soil and plant tissue. In: JACKSON, M. L. (Eds.). Soil chemical analyses. Englewood Cliffs: Prentice Hall, 1958. p. 183204.

PONCE, R. G. et al. Plant height as a factor in competition between nightshade and two horticultural crops (tomato and pepper). J. Hortic. Sci., v. 1, p. 53-460, 1996.

QASEM, J. R. Nutrient accumulation by weeds and their associated vegetable crops. J. Hortic. Sci. , v. 67, p. 189195, 1992.

RODRIGUES, J. R. M. Resposta do feijoeiro (cvs. Carioca e Pérola) a doses de nitrogênio e fósforo. 2001. 124 f. Tese (Doutorado em Fitotecnia) - Universidade Federal de Lavras, Lavras, 2001.

SHAFIQ, M. et al. Crop yields and nutrient uptake by rainfed wheat and mungbean as affected by tillage, fertilization, and weeding. J. Plant Nut., v. 17, p. 561-577, 1994.

SOUZA, L. S. et al. Teores de macro e micronutrientes e a relação $\mathrm{C} / \mathrm{N}$ de várias espécies de plantas daninhas. Planta Daninha, v. 17, p. 163-167, 1999.

TEYKER, R. H.; HOELZER, H. D.; LIEBL, R. A. Maize and pigweed response to nitrogen supply and form. Plant Soil, v. 135, p. 287-292, 1991.

TOMASO, J. M. Approaches for improving crop competitiveness through the manipulation of fertilization strategies. Weed Sci., v. 43, p. 491-497, 1995.

TUOR, F. A.; FROUD-WILLIAMS, R. J. Influence of nitrogen on competition between purple nutsedge, maize and soybean. Inter. J. Pest Manag., v. 48, p. 73-79, 2002.

UGEN, M. A.; WIEN, H. C.; WORTMANN, C. S. Dry bean competitiveness with annual weeds as affected by soil nutrient availability. Weed Sci., v. 50, p. 530-535, 2002.

VENGRIS, J.; COLBY, W. G.; DRAKE, M. Plant nutrient competition between weeds and corn. Agron. J. , v. 47, p. 213-216, 1955.

WAHLE, E. A.; MASIUNAS, J. B. Comparison of nitrogen use by two population densities of eastern black nightshade (Solanum ptycanthum). Weed Sci., v. 51, p. 394-401, 2003. 